\title{
Introdução da arte na psicoterapia: enfoque clínico e hospitalar
}

\author{
Introduction of art in psychotherapy: clinical and hospital \\ approaches
}

\author{
Erika Antunes VASCONCELLOS \\ Joel Sales GIGLIO²
}

\section{Resumo}

Este artigo visa discutir a introdução da expressão artística em contextos terapêuticos, procurando focalizar também o desenvolvimento da arteterapia com pacientes oncológicos. O tema foi discutido através de revisão bibliográfica, considerandose diferentes enfoques teóricos. Primeiramente, nos referimos à compreensão da arte como expressão subjetiva e à utilização de recursos artísticos no diagnóstico e na intervenção terapêutica. Em seguida, contextualizamos o tema, considerando também o ponto de vista da psicologia analítica junguiana com relação à linguagem imagética e à sua aplicação na psicoterapia. Por último, abordamos a arteterapia na assistência aos pacientes com câncer, destacando o enfoque hospitalar. Esse assunto tem sido pouco abordado na literatura científica em publicações nacionais, apesar da importante expansão nos grandes serviços de saúde. Tratase de um campo que ainda requer maior fundamentação teórica, principalmente no contexto institucional e na adequação à realidade brasileira.

Unitermos: arte-terapia; neoplasias; oncologia; psicologia; psicoterapia.

\begin{abstract}
This article brings up the artistic activity as a therapeutic practice for patients from oncology area. The theme is discussed through a bibliographic revision considering tree different focus. In the first one we refer to the understanding of Art as a subjective and symbolic expression and to the use of artistic resources during Psychotherapy. Secondly, we consider the Analytical Psychology position in relation to the imagery language. Last, we consider the application of Art Therapy in the assistance of oncology area patients. This issue has been undervalued in Brazilian scientific publications in spite of the growing practice of Art Therapy at Medical Centers in our country as a psychodynamic diagnosis or therapeutic resource. This field needs a better theoretical basis, mainly in the specific cultural and institutional Brazilian context.
\end{abstract}

Uniterms: art therapy; neoplasmas; oncology; psychology; psychotherapy.

1 Universidade Estadual de Santa Cruz, Departamento de Filosofia e Ciências Humanas. Campus Soane Nazaré de Andrade, Rod. Ilhéus, km 16, Itabuna, 45662000, Ilhéus, BA, Brasil. Correspondência para/Correspondence to: E.A. VASCONCELLOS. E-mail: <erikaantunes@uol.com.br>.

2 Universidade Estadual de Campinas, Faculdade de Ciências Médicas, Departamento de Psicologia Médica e Psiquiatria. Campinas, SP, Brasil 
Neste artigo, abordaremos a importância da arte como expressão da subjetividade, enfocando a prática clínica e hospitalar especialmente no que se refere ao cuidado destinado ao paciente com câncer. Primeiramente, destacaremos sua valorização em contextos terapêuticos, no campo da saúde mental, enfatizando também a perspectiva da psicologia analítica junguiana sobre a experiência imagética como expressão do inconsciente. Discutiremos, em seguida, a utilização da via artística no processo psicoterapêutico de pacientes oncológicos, delineando a prática da arteterapia no campo da psiconcologia.

\section{Expressão artística e mundo subjetivo}

A relação entre elaboração artística e expressão do mundo subjetivo passou a ser estabelecida como um importante foco de interesse de estudiosos representantes do meio científico e de integrantes do meio artístico a partir do final do século XIX, tendo maior repercussão a partir do início do século XX. Nesse período, portanto, alguns estudos considerados pioneiros demarcam o início das pesquisas na área.

Ferraz (1998), em seu livro "Arte e Loucura", descreve o momento histórico que se caracteriza pelo entrelaçamento entre áreas distintas, vislumbrando a interseção entre arte, psicologia, psiquiatria e psicanálise. Ela menciona vários importantes pesquisadores que inicialmente abordaram a interface: arte e saúde mental, dentre os quais podemos citar:Tardieu, em 1872; Simon, em 1876 e 1888; Lombroso, em 1889; Mohr, em 1906; Rejà, em 1907 e Prinzhorn, em 1922.

Com relação a esses pesquisadores, destacaremos aqui dois deles: Mohr e Prinzhorn. Mohr recebeu maior notoriedade científica após a publicação de um trabalho sobre a produção gráfica de doentes mentais. Ele influenciou vários outros estudos que contribuíram com a elaboração de alguns testes projetivos amplamente difundidos no campo da psicologia e da psicanálise. Prinzhorn, por sua vez, publicou em 1922 o livro cujo título em português é "A expressão da loucura". Essa publicação teve na época importante repercussão, valorizando as elaborações artísticas dos doentes mentais como produções de arte verdadeiramente reconhecidas, ressaltando a preservação das possibilidades criadoras desses indivíduos em detrimento da desintegração psíquica, característica dos transtornos mentais (Ferraz, 1998).

É interessante observarmos que, nesse momento histórico, o movimento psicanalítico também começou a eclodir, havendo confluência de interesses, já que a psicanálise, especialmente Freud, também buscava nessa época a compreensão da dinâmica psíquica a partir de estudos sobre as obras de alguns artistas consagrados, tanto nas artes plásticas (Freud, 1910/1970 e 1914/1974) como na literatura.

Na década de 20, entretanto, a arte começou a ser vista sob um enfoque mais amplo, contemplando não somente a possibilidade de diagnóstico, mas também sendo destacado seu aspecto terapêutico. Jung passou a introduzir a arte como parte do processo psicoterapêutico de seus pacientes, como veremos no próximo tópico.

Posteriormente, então, a esses primeiros estudos, a partir dos anos 40, a arteterapia foi realmente sistematizada, tendo como precursora Margareth Naumburg, nos Estados Unidos, que foi bastante influenciada pela abordagem freudiana; a autora trabalhou com a produção da arte espontânea durante a psicoterapia, considerando que as imagens espontaneamente projetadas nas produções gráficas e plásticas permitem a expressão do inconsciente.

O processo de arteterapia se baseia no reconhecimento de que os pensamentos e os sentimentos mais fundamentais do homem, derivados do inconsciente, encontram sua expressão em imagens e não em palavras. As técnicas da arteterapia se baseiam no conhecimento de que cada indivíduo, treinado ou não em arte, tem uma capacidade latente de projetar seus conflitos internos em forma visual. Quando os pacientes visualizam tais experiências internas, ocorre freqüentemente que eles se tornam mais articulados verbalmente (Naumburg, 1991, p.388).

Outros autores desenvolveram importantes trabalhos que contribuíram com a sistematização da arte no processo terapêutico. Podemos citar aqui Edith Kramer, desenvolvendo trabalhos na década de 50, Françoise Dolto, trabalhando com crianças na década de 70, Janie Rhyne, introduzindo a concepção da GestaltTerapia no trabalho com arte nos anos 70 e Natalie 
Rogers, aplicando a concepção da Teoria Centrada na Pessoa, desenvolvida por seu pai Carl Rogers, também na década de 70 (Andrade, 2000).

A arteterapia, entretanto, vem sendo considerada uma modalidade terapêutica com características próprias, abarcando em si algumas distinções técnicas e conceituais, diferenciando-se através de duas linhas de atuação: arte como terapia (art as therapy) e arte psicoterapia (art psychotherapy). Na primeira delas, o foco principal da terapia está no processo artístico, considerando suas propriedades curativas. Na segunda vertente, os recursos artísticos são utilizados amplamente durante o processo psicoterapêutico, acrescentando a via imagética e pictórica na comunicação entre paciente e psicoterapeuta (nesse caso, com a utilização de técnicas de artes plásticas). Nessa segunda linha de atuação, o fazer arte ocorre dentro de um enquadre psicoterapêutico específico, seguindo princípios, técnica, embasamento teórico e objetivos que visam fundamentalmente o desenvolvimento emocional do indivíduo, repercutindo na ampliação de potencialidades criativas (Andrade, 2000).

Sobre essa diversidade, Pain e Jarreau (1996) esclarecem a necessidade de adequação da terapêutica adotada (referindo-se à linha de atuação em arteterapia) à população de pacientes (em função das indicações terapêuticas) e ao próprio ambiente disponível. Esses pontos são discutidos, enfatizando-se a possibilidade dessa intervenção ser realizada no contexto institucional, como no caso da prática hospitalar, na qual as condições de atendimento e a dinâmica assistencial poderão dificultar a preservação do enquadre psicoterapêutico, sendo indicada uma atitude terapêutica mais flexível, por exemplo, com relação aos horários e duração das sessões, à possibilidade de entrada e saída de integrantes nos grupos terapêuticos e ao local de realização dos atendimentos. Além disso, devemos também pontuar que a arteterapia não é uma prática exclusiva do psicólogo, visto que profissionais com outras formações acadêmicas têm se especializado nessa área, desenvolvendo intervenções mais adequadas às suas formações de origem e, nesses casos, não seguindo as peculiaridades da técnica pertinentes à psicoterapia.

De maneira geral, essa revisão da bibliografia sobre o tema aqui discutido nos mostra que o alcance da arteterapia é bastante amplo, pois como intervenção visa desenvolver recursos físicos, cognitivos e emocionais, propiciar o desenvolvimento de habilidades e de potencialidades, favorecendo a utilização de recursos internos na resolução de conflitos, e estimular a livre expressão, oferecendo espaço continente para a externalização de aspectos conscientes ou não do mundo subjetivo.

No entanto, como veremos adiante, considerando nosso intuito de abordar neste artigo a introdução da arte na psicoterapia, enfatizamos a visão psicodinâmica do processo arteterapêutico. Nessa perspectiva, visamos compreender os aspectos simbólicos que se manifestam na elaboração de uma produção artística (contidos também na produção final), analisados como conteúdos projetados durante as sessões de arteterapia, podendo ser integrados à consciência, desencadeando um processo de transformação intrapsíquica.

No Brasil, o enfoque psicodinâmico fundamentou os trabalhos pioneiros na introdução da arte como proposta terapêutica realizada junto a pacientes psiquiátricos institucionalizados. Esses trabalhos foram desenvolvidos por Osório César em São Paulo e por Nise da Silveira no Rio de Janeiro, repercutindo profundamente na proposta atual do arteterapeuta.

Osório César, baseando-se no referencial freudiano, é considerado o precursor da perspectiva terapêutica da arte no Brasil. Sua prática foi realizada com pacientes internos do Hospital Psiquiátrico do Juqueri e seu primeiro artigo sobre esse tema, datado de 1925, intitula-se: "A Arte Primitiva nos Alienados" (Ferraz, 1998).

Já Silveira, orientada sob a perspectiva junguiana, também desenvolveu e coordenou ateliês de arte com pacientes psiquiátricos internados, sendo autora de duas obras de suma importância: "Imagens do Inconsciente" (1981) e "O Mundo das Imagens" (1992). Ela rompeu barreiras, trazendo inovações com suas propostas terapêuticas e recebendo notoriedade nacional e internacional, principalmente após manter contato com Jung, que valorizou a importante dimensão de seu trabalho. Esse contato ocorreu quando Nise da Silveira passou a observar um grande número de mandalas entre as produções pictóricas de seus 
pacientes, enviando correspondência a Jung, em 1954 com o objetivo de obter mais informações sobre tais produções circulares. A partir de então, houve um estreitamento na relação entre os dois, abrindo portas inclusive para a exposição de obras produzidas pelos pacientes do Centro Psiquiátrico do Rio de Janeiro, intitulada: "A Esquizofrenia em Imagens", que ocorreu em Zurique em paralelo ao II Congresso Internacional de Psiquiatria (Silveira, 1981).

A partir desses trabalhos pioneiros, que tiveram repercussão nacional e internacional, outros focos têm surgido e, pouco a pouco, tem-se ampliado a utilização terapêutica da arte para outros seguimentos da saúde, voltando-se a populações com diferentes comprometimentos e doenças.

\section{Arte na psicoterapia sob a perspectiva da psicologia analítica junguiana}

Como temos visto, os estudos de Jung influenciaram amplamente o campo da arteterapia, trazendo à tona discussões mais profundas em torno da importância do mundo imagético na compreensão do psiquismo e, conseqüentemente, valorizando a análise das imagens simbólicas projetadas nas produções artísticas dos pacientes dentro do enquadre psicoterapêutico. Suas descobertas e reflexões abalaram os paradigmas do pensamento ocidental pela inclusão de novos enfoques a respeito dos processos psíquicos e da dimensão transcendente do ser humano.

Segundo Jung, o princípio originário que rege a natureza humana é o mundo das imagens e, portanto, toda experiência humana tem seu desdobramento a partir dessa premissa. Ele atribui à imagem arquetípica - que também foi nomeada como imagem primordial papel fundamental na constituição de todos os processos mentais, considerando que aí se configuram as vivências primordiais da humanidade (Kugler, 2002).

Jung (1921/1991, p.418) estabelece diferenciação entre imagens de caráter pessoal e de caráter impessoal. A primeira nos remete a conteúdos do inconsciente pessoal e da experiência consciente. A última, entretanto, diz respeito à imagem primordial quando representa manifestação de ordem coletiva, apresentando características mitológicas. Nessa perspectiva, ele define o fenômeno imagético como "uma expressão concentrada da situação psíquica como um todo", distinguindo-o de qualquer manifestação patológica (onde costuma ocorrer distorção da realidade), sendo um processo interno. A expressão imagética, portanto, agrega apenas conteúdos do inconsciente constelados naquele momento, visto que a seleção dos conteúdos relevantes e irrelevantes à formação da imagem é um processo consciente.

Quanto aos arquétipos, esses a presentam certa autonomia e carga energética que atrai conteúdos do consciente que lhes revestem com roupagens adequadas à época e à circunstância pela qual são evocados. São, portanto, "elementos estruturais numinosos" que dão a fôrma para que conteúdos do consciente se moldem e, assim, possam tornar-se perceptíveis. Dessa maneira, considerando o limiar entre inconsciente coletivo, inconsciente pessoal e consciente, vislumbramos a formação da imagem simbólica. Aliás "nunca se pode encontrar o arquétipo em si de maneira direta, mas apenas indiretamente, quando se manifesta no símbolo ou no sintoma ou no complexo" (Jacobi, 1995, p.73).

Portanto é importante destacar que arquétipo e símbolo não são conceitos equivalentes. O arquétipo é o centro energético que poderá ser constelado ao emergir na forma de símbolo. Esse último, entretanto, requer um esboço arquetípico, exercendo função transformadora da energia psíquica. O símbolo também agrega função terapêutica que não se restringe à imagem em si, contemplando o significado que transcende a própria imagem (Tommasi, 2003).

Estando ligado à vida e ao ser vivo, o arquétipo condensa imagem e emoção, sendo conseqüentemente revestido por sentimento e dinamismo. Nesse sentido, sua compreensão apenas é possível levando-se em consideração a maneira indicada pelo sujeito que o constela, não podendo ser isolado e nem entendido arbitrariamente (Jung, 1935/1998).

Ao interpretarmos um símbolo, procuramos decifrar a realidade invisível que se oculta através do que nos é perceptível. No entanto, mesmo sendo interpretado, os significados nele implícitos nunca se esgotam, pois quando seu significado é completamente decifrado, ocorre a morte do símbolo (Kast, 1997a).

Na história da humanidade, a presença de símbolos sempre foi marcante. Tudo é passível de se 
tornar símbolo, desde os elementos da natureza ou os próprios produtos da ação humana, até os elementos abstratos. Jaffé (1964), ao abordar o simbolismo nas artes plásticas, retrata o longo trajeto histórico dessa forma de expressão, identificando aspectos simbólicos desde a pré-história, a partir dos registros de pinturas rupestres, até os tempos atuais.

Nas artes, em geral, observam-se inúmeras projeções do simbolismo humano, nos remetendo às imagens pessoais e impessoais (arquetípicas) descritas tão amplamente por Jung, o que justifica a grande influência do pensamento junguiano no desenvolvimento das práticas arteterapêuticas.

Tanto na produção de um artista quanto na produção de um paciente dentro de um contexto psicoterapêutico, a imagem que emerge durante o processo expressivo reúne aspectos da psique do sujeito que são constelados naquele específico momento (Giglio, 1992; Zimmermann, 1992).

O próprio Jung experienciou a arte tanto na vida pessoal (Jung, 1963/1984) quanto na intervenção com seus pacientes em psicoterapia. Segundo ele:

Os elementos pictóricos que não correspondem a nenhum lado externo devem provir do 'intimo'.. Como esse 'íntimo' é invisível e inimaginável mas pode influenciar a consciência de um modo muito eficaz, levo os meus pacientes, sobretudo os que sofrem de tais efeitos, a reproduzi-los da melhor maneira possível, através da forma pictórica. A finalidade desse 'método de expressão' é tornar os conteúdos inconscientes acessíveis e, assim, aproximá-los da compreensão. Com essa terapêutica consegue-se impedir a perigosa cisão entre a consciência e os processos inconscientes. Todos os processos e efeitos de profundidade psíquica, representados pictoricamente, são, em oposição à representação objetiva ou 'consciente', simbólicos, quer dizer, indicam da melhor maneira possível, e de forma aproximada, um sentido que, por enquanto, ainda é desconhecido (Jung, 1935/1985, p.120)

Como podemos compreender a partir dos estudos de Silveira (1992), as imagens internas são subjetivas por retratarem a realidade psíquica em sua amplitude (consciente e inconsciente pessoal), mas podem ser universais, pois muitas vezes apresentam motivos arquetípicos compartilhados com toda a humanidade (inconsciente coletivo).

Essa autora valorizou a análise da série de produções artísticas de pacientes psiquiátricos (como Jung propunha com a análise da seqüência de sonhos), observando a repetição de motivos e a presença do fluxo de imagens do inconsciente carregadas de energia psíquica, inclusive na representação de temas mitológicos.

Outra autora que estudou os aspectos terapêuticos do ato de pintar e desenhar foi Zimmermann (1992). Ela destacou que neste processo terapêutico ocorre a canalização da energia contida por meio da catarse, podendo desencadear a redistribuição da energia psíquica durante a elaboração artística, mencionando a oportunidade de oferecimento de espaço continente às projeções de conteúdos inconscientes durante o processo expressivo, discutindo também a questão da análise e interpretação das produções dos pacientes. Sobre esse último tema, considera que uma imagem pictoricamente produzida não é possível de ser compreendida e, portanto, interpretada de maneira adequada, se não tivermos informações prévias sobre a história de vida do sujeito que a elaborou (Zimmermann, 1992).

\section{Arteterapia no cuidado ao paciente com câncer}

Como temos observado até aqui, a expressão imagética através da linguagem gráfica e pictórica (pela via das artes plásticas) vem sendo reconhecida pelos profissionais de saúde mental pelas suas potencialidades terapêuticas. A utilização desses recursos também tem atraído cuidadores de pacientes portadores de doenças somáticas. Como conseqüência, a utilização da arte no processo psicoterapêutico também tem sido aplicada não só em hospitais e clínicas psiquiátricas com indivíduos que sofrem de transtornos mentais, mas também nos hospitais gerais e nas clínicas de outras especialidades, sobretudo com indivíduos que apresentam doenças crônico-degenerativas.

No campo da psiconcologia, considerando as várias modalidades terapêuticas, devemos destacar a 
arteterapia, pressupondo-se a importância da transformação psíquica gerada pela experiência criativa que pode ser propiciada ao indivíduo que adoece com câncer, ajudando-o a elaborar conflitos e a enfrentar experiências de dor, perda e luto decorrentes da doença e do próprio tratamento. Identificamos aqui um dos pontos de conexão que focalizamos neste artigo, considerando a interseção entre arte, psicologia e oncologia. Esse enfoque pode estar vinculado à subárea denominada "arteterapia médica" (Medical Art Therapy), conceito que não é utilizado no Brasil, mas que se refere à abordagem arteterapêutica de pacientes com doenças somáticas.

O artista inglês Adrian Hill é considerado um dos pioneiros nessa área. Ele desenvolveu, já na década de 40, o trabalho de arte com tuberculosos internados em um sanatório, aplicando o termo arteterapia para designar a intervenção baseada na elaboração de trabalhos artísticos com pacientes em isolamento, visando promover ação terapêutica ao oferecer recursos expressivos que contribuíssem com a redução dos sintomas depressivos nessa população (Luzzatto \& Gabriel, 1998; Malchiodi, 1999; Wood, 1998). Na Inglaterra, esse trabalho pioneiro teve importantes repercussões e, pouco a pouco, essa área de interesse foi sendo compartilhada por outros profissionais, tendo se constituído em 1993 em uma subárea dentro da Associação Britânica de Arteterapeutas (British Association of Art Therapists - BAAT), denominada The Creative Response, voltada ao desenvolvimento da arteterapia nos cuidados paliativos, atuando, portanto, na assistência integral ao paciente fora de possibilidades terapêuticas de cura e ao paciente em fase terminal (Wood, 1998).

Atualmente, podemos observar que os grandes centros de oncologia vêm gradualmente incluindo em seus programas de assistência a concepção de interdisciplinaridade. As tendências atuais na área da saúde têm caminhado para a ruptura de antigos paradigmas que encaravam a doença como algo que pudesse ser tratado independentemente da atenção ao sujeito que adoece (Vasconcellos, 2000).

Estudos científicos voltados ao processo saúdedoença têm focalizado a qualidade de vida e a saúde mental do paciente oncológico, mostrando que o objetivo terapêutico oferecido a esse doente não deve ter como meta, exclusivamente, a cura, a redução do tumor, o aumento da sobrevida ou o alívio da dor física; mas deve incluir a melhoria da qualidade de vida e a possibilidade de resgate da dignidade e da motivação para o viver (Carvalho, 1994; Holland, 1998).

Temos observado, a partir de alguns estudos baseados em nossa prática clínica, que o processo artístico propiciado ao paciente com câncer pode favorecer a ressignificação da própria vida, na medida em que facilita o encontro de algumas diretrizes para se lidar com a difícil realidade vivenciada durante a trajetória de doença e tratamento, num movimento de reconstrução da história pessoal e de contato com os próprios sentimentos e fantasias (Vasconcellos, Perina \&Vanni, 1996; Vasconcellos \& Perina, 2002; Vasconcellos \&Giglio, 2003; Vasconcellos, 2004).

A experiência de adoecimento e de realização do tratamento oncológico (quimioterapia, radioterapia, cirurgia) gera limitações e conflitos no paciente e em seus familiares, mobilizando inseguranças, temores e angústias. A expressão de tais vivências que representam aspectos do mundo interno é um dos principais focos da arteterapia com essa população uma vez que, além dos conteúdos intencionalmente externalizados nas produções (aspectos conscientes), lidamos também com conteúdos simbólicos (aspectos inconscientes) de extrema relevância para todo o processo de transformação e ressignificação, sendo esses fatores imprescindíveis à proposta arteterapêutica em sua perspectiva psicodinâmica.

Na área de cuidados paliativos, existem algumas peculiaridades do trabalho arteterapêutico em função das características da população atendida, sendo alcançados alguns resultados bastante expressivos. Com relação a esse tema, Wood (1998) destaca que essa intervenção pode objetivamente auxiliar o paciente a compreender sua real situação, enfrentar mudanças relacionadas à imagem corporal, amenizar a dor emocional pertinente ao processo do adoecer e do morrer; aumentar sua autonomia e confiança, fortalecendo algumas habilidades para enfrentar a situação de doença, facilitar a expressão de sentimentos e fortalecer a relação com a equipe de saúde.

Luzzatto e Gabriel (1998) descrevem duas abordagens no campo da arteterapia: uma delas voltada às propriedades curativas do processo intrapsíquico 
criativo e outra voltada à utilização terapêutica das relações interpessoais no processo artístico. Essas autoras têm desenvolvido trabalhos no campo da arteterapia aplicada à oncologia e, sendo assim, consideram que tal intervenção permite ao profissional maior flexibilidade por poder utilizar recursos artísticos em abordagens psicoterapêuticas com ênfase no apoio psicológico, no trabalho cognitivo ou nos processos psicodinâmicos, levando em consideração que a população de pacientes oncológicos não é homogênea, apresentando demandas bastante distintas que poderão ser supridas mais amplamente.

Como podemos ver, considerando o enfoque psicodinâmico, os processos inconscientes também podem ser compreendidos e elaborados durante a arteterapia com pacientes portadores de doenças somáticas, especialmente no campo da oncologia. Nessa perspectiva, Dreifuss-Kattan (1990) refere-se à postura do arteterapeuta diante do paciente oncológico, valorizando a atitude de acolhimento. Ele deverá ser capaz de acolher as imagens projetadas durante o processo criativo, mostrando continência aos conteúdos do mundo interno desse sujeito: suas ansiedades, angústias, temores e desejos, tornando possível que a figura do arteterapeuta seja introjetada por ele como objeto bom. Essa autora ressalta ainda que a possibilidade de expressão da realidade interna e a conscientização de alguns aspectos intrapsíquicos poderão auxiliar o sujeito com câncer em seu processo de auto-reparação, destacando também que as produções artísticas desses pacientes têm significado especial, representando a fantasia de imortalidade e a permanência de um vínculo positivo que sobrevive mesmo após a morte ou o término do tratamento.

Luzzatto (1998) estabelece importante diferenciação entre atuação arteterapêutica no campo da psiquiatria e atuação destinada aos pacientes com câncer. Na primeira área citada, a intervenção tem como foco o mundo interno do paciente que sofre de um transtorno psíquico. Na segunda área, considera-se a existência do comprometimento físico e da dor também de origem orgânica, que se expressam através do sofrimento psíquico e vice-versa. Assim, a proposta terapêutica deverá reconhecer a dimensão corporal, atendendo necessidades de alívio, de relaxamento e de experiências tranquilizadoras. Ainda assim, o respeito às necessidades individuais de cada paciente implicará o desenvolvimento de técnicas adequadas para cada situação.

Luzzatto (1998) também chama a atenção para a"cultura do pensamento positivo" compartilhada pelos pacientes com câncer. Nessa perspectiva, ocorre a crença de que o pensamento negativo do sujeito levaria à progressão da doença ou a recidiva e, assim, ao tentar se opor a esse destino, os pacientes tenderiam a enfrentar o tratamento mostrando atitudes que evidenciam força e otimismo, ocultando algumas reações emocionais indesejadas. Isso denota uma articulação de defesas que os distancia do sofrimento, sendo constantemente observado o mecanismo de negação diante do contato com situações dolorosas. 0 fato de não compartilhar vivências e sentimentos não significa que eles não existam. No processo arteterapêutico, o objetivo é a ampliação da consciência, entretanto, em função dessas resistências e defesas fortemente articuladas, o profissional deverá ser cauteloso, respeitando os limites que o próprio sujeito nos mostra durante seu tratamento. Assim, no espaço arteterapêutico, trabalhamos com a expressão simbólica através das imagens elaboradas nas produções artísticas (valorizando a representação gráfica e pictórica), sendo externalizadas vivências de sofrimento e morte sem que seja necessário nomeá-las.

Minar (1999) em seu trabalho com pacientes oncológicos observa a presença do que denominou imagens do "agressor" e imagens do "curador" (images of the hurter and the healer). Como "agressor", surgem imagens relacionadas à própria doença, aos sentimentos de pesar e às reações decorrentes do câncer, representando dor, sofrimento, ameaças e temores. Nuvens negras, vulcões, rochas pontiagudas, explosões, ervas daninhas, furacões (vendavais), redemoinhos de água, serpentes e florestas aparecem nas produções artísticas dos pacientes. Cuidando do "machucado", pacientes e terapeuta trabalham em conjunto com o objetivo de melhorar a qualidade de vida, investindo na recuperação de forças saudáveis internas para combater a doença. Ao mobilizar essas forças, as imagens do "curador"emergem, às vezes até nas mesmas produções onde as imagens do "agressor" estão presentes. Assim, as imagens do "curador"representam símbolos pessoais: metáforas de Deus, família, amigos, surgindo também 
fontes de luz, fontes de água, novos horizontes, figuras em crescimento, figuras místicas, mandalas e símbolos de amor. Segundo essa autora, essas imagens simbólicas ajudam os pacientes em seus processos de cura, ajudando-os a lidar com o "machucado".

Os conteúdos descritos por Minar (1999) podem ser também compreendidos como representações de polaridades que retratam ação da função compensatória da psique através da busca por equilíbrio. É freqüente encontrarmos nas produções gráficas e pictóricas de alguns pacientes oncológicos esses pólos opostos muito bem demarcados, pois nesse contexto observase a expressão de emoções ou experiências dolorosas e angustiantes (imagens simbólicas representando perda, morte, sofrimento), incluindo, também, na mesma produção, imagens simbólicas compensatórias ligadas ao impulso de vida, como, por exemplo, nascimento, germinação, crescimento, saúde (Vasconcellos, 2004).

Através da riqueza simbólica do mundo imagético de pacientes com doenças somáticas, representando um diálogo do sujeito com seu próprio corpo, nos aproximamos da interação corpo-mente, conforme nos dizKast (1997b, p.172):"O fluxo das imagens interiores pode ter sua origem em percepções físicas. Em geral, o corpo pode assumir o lugar dos motivos a partir dos quais criamos nossas representações."

Dessa maneira, a dimensão psíquica relacionada à experiência do adoecer pode ser desvelada, pois os pacientes, em geral, projetam imagens muito significativas em suas produções artísticas, trazendo à tona conteúdos simbólicos pertinentes à situação pessoal na interação com o corpo e à dimensão coletiva. As imagens simbólicas que surgem nas produções auxiliam o sujeito a entrar em contato com seu mundo interior.

\section{Considerações Finais}

Como podemos observar, diversas correntes teóricas têm reconhecido a importância da arte no diagnóstico e na intervenção terapêutica em áreas de atuação onde a psicologia e a psiquiatria passaram a ter representatividade. Ainda assim, observamos que, no contexto hospitalar com pacientes portadores de doenças crônicas e na área da psiconcologia, a interface entre elaboração artística e aspectos relacionados ao adoecer tem sido pouco abordada em trabalhos científicos realizados no Brasil, recebendo maior destaque em publicações internacionais ainda em fase de expansão. Estudos nessa área são necessários para o aprimoramento dessa nova prática terapêutica.

Nesse sentido, é importante destacar que o crescente avanço da medicina no tratamento de diversas doenças crônicas requer a inclusão de novas intervenções terapêuticas, oferecidas pelas equipes interdisciplinares, que contemplem também o indivíduo em sua totalidade psíquica, acompanhando as ações diretamente voltadas ao corpo do sujeito doente e se adequando à rotina hospitalar, visando resgatar a perspectiva humana na assistência à saúde.

\section{Referências}

Andrade, L. Q. (2000). Terapias expressivas. São Paulo: Vector.

Borgmann, E. (2002). Art therapy with three women diagnosed with cancer. The Arts in Psychotherapy, 29 (5), 245-250.

Carvalho, M. M. M. J. (Org.) (1994). Introdução à psiconcologia. Campinas: Editorial Psy II.

Dreifuss-Kattan, E. (1990). Cancerstories. Creativity and self-repair. Hillsdale: Analylic Press.

Ferraz, M. H. C. T. (1998). Arte e loucura: limites do imprevisível. São Paulo: Lemos Editorial.

Freud, S. Leonardo da Vinci e uma lembrança de sua infância (1970). In S. Freud. Edição standard brasileira das obras completas de Sigmund Freud. (Vol.11, pp.53-124). Rio de Janeiro: Imago. (Publicado originalmente em 1910).

Freud, S. O Moisés de Michelangelo (1974). In S. Freud. Edição standard brasileira das obras psicológicas completas de Sigmund Freud (Vol. 13, pp.249-279). Rio de Janeiro: Imago. (Publicado originalmente em 1914).

Giglio, J. S. (1992). Técnicas expressivas como recurso auxiliar na psicoterapia: perspectiva junguiana. Boletim de Psiquiatria, $27(1), 21-25$.

Holland, J. C. (Org.) (1998). Psycho-oncology. New York: Oxford University Press.

Jacobi, J. (1995). Complexo arquétipo símbolo na psicologia de C.G. Jung. São Paulo: Cultrix.

Jaffé, A. (1964). O simbolismo nas artes plásticas. In C.G. Jung (Org.), O homem e seus símbolos (pp.230-271). Rio de Janeiro: Nova Fronteira.

Jung, C. G. (1984). Memória, sonhos e reflexões. Rio de Janeiro: Nova Fronteira. (Publicado originalmente em 1963).

Jung, C. G. (1985). O Espírito na arte e na ciência. Petrópolis: Vozes. (Publicado originalmente em 1932). 
Jung, C. G. (1991). Tipos psicológicos. Petrópolis: Vozes. (Publicado originalmente em 1921).

Jung, C. G. (1998). A vida simbólica. Petrópolis: Vozes. (Publicado originalmente em 1935).

Kast, V. (1997a). A dinâmica dos símbolos: fundamentos da psicoterapia junguiana. São Paulo: Edições Loyola.

Kast, V. (1997b). A imaginação como espaço de liberdade: diálogos entre o ego e o inconsciente. São Paulo: Edições Loyola.

Kern-Pilch, K. (1980). Anne: an illustrative case of art therapy with a terminally ill patient. American Journal of Art Therapy, 20 (1), 3-11.

Kugler, P. (2002). Imagem psíquica: uma ponte entre o sujeito e o objeto. In P. Young-Eisendrath \& T. Dawson (Orgs.) Manual de Cambridge para estudos junguianos (pp. 85-97). Porto Alegre: Artmed.

Luzzatto, P. (1998). From psychiatry to psycho-oncology: personal reflections on the use of art therapy with cancer patients. In M. Pratt \& M. J. M. Wood (Orgs.), Art therapy in palliative care. The creative response (pp.169-175). London: Routledge.

Luzzatto, P., \& Gabriel, B. (1998). Art psychotherapy. In J. C. Holland (Org.), Psycho-oncology (pp.743-757). New York: Oxford University Press.

Malchiodi, C. A. (1999). Introduction. Art therapy and medicine: powerful partners in healing. In C. A. Malchiodi (Org.) Medical art therapy with adults (pp.13-23). London: Jessica Kingsley Publishers.

Minar, V. M. (1999). Art therapy and cancer: images of the hurter and healer. In C. A. Malchiodi (Org.), Medical art therapy with adults (pp.227-242). London: Jessica Kingsley Publishers.

Naumburg, M. (1991). Arteterapia: seu escopo e função. In E. F. Hammer (Org.), Aplicações clínicas dos desenhos projetivos (pp.388-392). São Paulo: Casa do Psicólogo.

Pain, S., \& Jarreau, G. (1996). Teoria e técnica da arte-terapia. Porto Alegre: Artes Médicas.
Rudloff L. (1985). Michael: an illustrated study of a young man with cancer. American Journal of Art Therapy, 24 (2), 49-62.

Silveira, N. (1981). Imagens do inconsciente. Rio de Janeiro: Alhambra.

Silveira, N. (1992). O mundo das imagens. São Paulo: Ática.

Tommasi, S. M. B. (2003). A dinâmica de complexos inconscientes por meio de símbolos religiosos nas artes plásticas de pacientes psiquiátricos. Tese de doutorado não-publicada, Universidade Metodista de São Paulo.

Vasconcellos, E. A. (2000). Enfrentando a doença no hospital: uma abordagem de pacientes com doenças crônicas. Dissertação de mestrado não-publicada, Universidade Estadual Campinas.

Vasconcellos, E. A. (2004). Imagens simbólicas no adoecer:estudo descritivo sobre o processo arteterapêutico de pacientes oncológicos. Tese de doutorado não-publicada, Universidade Estadual de Campinas.

Vasconcellos E. A., \& Giglio, J. S. (2003). Art therapy in psychooncology: the subjective expression of the illness [Resumo]. Psycho-Oncology, 12 (4 Supplement), 202.

Vasconcellos, E. A., \& Perina, E. M. (2002). Adolescence and Cancer: the use of stories and drawings in psychological assistence in group with adolescents [Resumo]. Medical \& Pediatric Oncology, 39 (4), 364.

Vasconcellos, E. A., Perina, E. M., \&Vanni, R. F. (1996). A adolescência sob o estigma do câncer. Revista de Psicologia Hospitalar, 12 (2), 30-35.

Wood, M. J. M. (Org.) (1998). Art therapy in palliative care: the creative response. London: Routledge.

Zimmermann, E. B. (1992). Integração de processos interiores no desenvolvimento da personalidade. Dissertação de mestrado não-publicada, Universidade Estadual de Campinas.

Recebido em: 18/9/2003

Versão final reapresentada em: 26/7/2006

Aprovado em: 12/4/2007 
